\title{
Increased mortality among HIV-positive men on antiretroviral therapy: survival differences between sexes explained by late initiation in Uganda
}

This article was published in the following Dove Press journal:

HIVIAIDS - Research and Palliative Care

28 May 2013

Number of times this article has been viewed

\author{
Steve Kanters ${ }^{1,3}$ \\ Margaret Nansubuga ${ }^{2}$ \\ Daniel Mwehire ${ }^{2}$ \\ Mary Odiit ${ }^{2}$ \\ Margaret Kasirye ${ }^{2}$ \\ William Musoke ${ }^{2}$ \\ Eric Druyts ${ }^{3}$ \\ Sanni Yaya ${ }^{3}$ \\ Anna Funk ${ }^{3}$ \\ Nathan Ford ${ }^{4,5}$ \\ Edward J Mills 3,6 \\ 'Faculty of Health Science, Simon \\ Fraser University, Burnaby, BC, \\ Canada, ${ }^{2}$ Mildmay Uganda, Kampala, \\ Uganda; ${ }^{3}$ Faculty of Health Sciences, \\ University of Ottawa, Ottawa, ON, \\ Canada; ${ }^{4}$ Médecins Sans Frontières, \\ Geneva, Switzerland; ${ }^{5}$ Centre for \\ Infectious Disease Epidemiology and \\ Research, University of Cape Town, \\ South Africa; ${ }^{6}$ Stanford Prevention \\ Research Center, Department of \\ Medicine, Stanford University School \\ of Medicine, Stanford, CA, USA
}

Correspondence: Edward J Mills Faculty of Health Sciences, University of Ottawa, 43 Templeton Street, Ottawa KIN 6XI, Canada Email edward.mills@uottawa.ca
Background: We aimed to assess the relationship between gender and survival among adult patients newly enrolled on antiretroviral therapy (ART) in Uganda. We also specifically examined the role of antenatal services in favoring women's access to HIV care.

Methods: From an observational cohort study, we assessed survival and used logistic regression and differences in means to compare men and women who did not access care through antenatal services. Differences were assessed on measures of disease progression (WHO stage and CD4 count) and demographic (age, marital status, and education), behavioral (sexual activity, disclosure to partner, and testing), and clinical variables (hepatitis B and C, syphilis, malaria, and anemia). A mediational analysis that considered gender as the initial variable, time to death as the outcome, initial CD4 count as the mediator, and age as a covariate was performed using an accelerated failure time model with a Weibull distribution.

Results: Between 2004 and 2011, a total of 4775 patients initiated ART, and after exclusions 4537 (93.2\%) were included in analysis. Men initiating ART were more likely to have a WHO disease stage III or IV (odds ratio: 1.46, 95\% confidence interval [CI]: 1.29-1.66), and lower CD4 cell counts compared to women (median baseline CD4 124 cells $/ \mathrm{mm}^{3}$, interquartile range [IQR]: $43-205$ versus 147 cells $/ \mathrm{mm}^{3}$, IQR: $68-212, P$-value $\left.<0.0001\right)$. Men were at an increased risk of death compared to women (hazard ratio: 1.38, 95\% CI: 1.03-1.83). Baseline CD4 cell counts accounted for $43 \%$ of the increased risk of death in men ( $95 \%$ CI: $22 \%-113 \%)$. Access to care via antenatal services did not explain differences in outcomes.

Conclusion: In this cohort there is a marked increase in risk of mortality for men and approximately half of it can be attributed to their later engagement in care. More effort is required to engage men in care in a timely manner.

Keywords: HIV, antiretroviral therapy, gender, Uganda, antenatal care, mortality

\section{Introduction}

The provision of antiretroviral therapy (ART) in sub-Saharan Africa (SSA) has resulted in reduced mortality, morbidity, and an increase in life expectancy. ${ }^{1,2}$ Despite these successes, approximately 59\% of all people in Africa remain without treatment despite being considered eligible. ${ }^{3}$ Also, for those in care, improvements are required along every step of the care cascade to improve health outcomes for both individuals and the population. ${ }^{4}$

The first entry point to care is HIV testing, which is often accessed through providerinitiated testing at the health center. In many settings, provider-initiated testing has favored women and children, usually in the antenatal care (ANC) period. ${ }^{5,6}$ There has been recent growing recognition that men are disadvantaged because no equivalent routine testing opportunity exists for them, ${ }^{7}$ and this is considered at least partly to 
account for the fact that men initiate ART later than women, ${ }^{8}$ and have worse outcomes on antiretroviral therapy compared to women. ${ }^{9-13}$

In this study, we aimed to determine mortality between sexes after initiation of ART in the greater Kampala area of Uganda. We further sought to determine whether differences in disease progression across the sexes could be explained by differential access to care via ANC services, and estimated how much of the increased risk of mortality in men can be explained by later ART initiation.

\section{Method}

\section{Data and study population}

All patient data for this study is from the Mildmay Uganda observational cohort (MUg). ${ }^{14}$ Mildmay is a medical service organization providing ART and other healthcare services to the HIV-positive community in Uganda. The organization opened in 1998 in order to provide palliative outpatient care for people living with HIV/AIDS, and to be a teaching and training center for HIV/AIDS healthcare personnel. This study was restricted to patients who initiated ART between January 2004 and April 2011, were aged 14 years or older at baseline, and had completed the selection form. Selection forms contain baseline data including whether a woman was pregnant or eligible for ART for prevention of mother to child transmission (PMTCT). To the best of our knowledge, selection forms were missing completely at random (ie events leading to missing selection forms are independent of variables of interest). Patient level data are collected on all patients and recorded into a central server.

\section{Outcome measures and prediction variables}

The primary outcome was all-cause mortality throughout the study period that ended in October 2011 to ensure that patients had the possibility of at least 6 months of followup time. Most deaths were reported by family members or recorded at hospital locations. Time was measured beginning at first ART date and ending at either date of death, 6 months after last visit, or at end of study period, respectively. Followup time beyond the last visit is justified by the fact that death is externally observed. The Mildmay program engages community adherence supporters to assist with patient retention in care. The principal explanatory variables of interest were sex, baseline CD4-cell counts and World Health Organization disease stage. Baseline CD4 cell counts were obtained within 6 months before starting ART. During the observation period, the Ugandan national guidelines stipulated that patients were considered eligible for ART if they had a CD4 count $\leq 200$ cells $/ \mathrm{mm}^{3}$ (this was changed to $\leq 350$ cells $/ \mathrm{mm}^{3}$ in 2012). We also measured demographic (age, marital status, and education), behavioral (sexual activity, disclosure to partner, and testing), and clinical variables (hepatitis B and C, syphilis, malaria, and anemia). Women were deemed to be in antenatal care if they reported either being pregnant at baseline or being PMTCT eligible.

\section{Analyses}

To determine the existence of any important differences between men and women with respect to demographic, behavioral, and clinical variables in the full cohort, we used Fisher's exact and Wilcoxon Rank Sum tests. Logistic regression and confidence intervals for difference in means were used to estimate the differences in disease progression, as defined by WHO disease stage and baseline CD4 cell counts, in men and women. These were applied to samples with and without women accessing care through ANC. We used Kaplan-Meier survival curves to demonstrate mortality over time in both the full and restricted cohorts. We applied a weighted analysis whereby $30 \%$ of patients lost to follow-up were assumed to be dead, weighted by baseline CD4 and age, as suggested by Egger et al. ${ }^{15}$

Mediational modeling was conducted to estimate the proportion of increased risk of mortality in men attributable to later ART initiation ${ }^{16}$ using recently developed methods for survival analysis. ${ }^{17-19}$ Mediator variables are distinguished from confounders in that they lie on the causal pathway. Figure 1 displays the pathways from initial variable to outcome. The effect of the initial variable (gender) summed across all pathways is its total effect. As shown in Figure 1, the total effect can be partitioned into the direct effect and

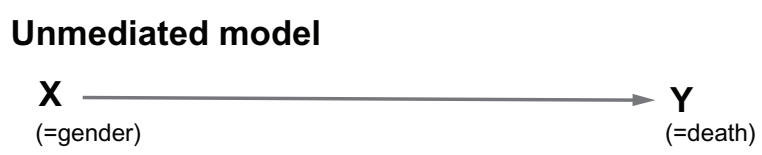

Mediated model

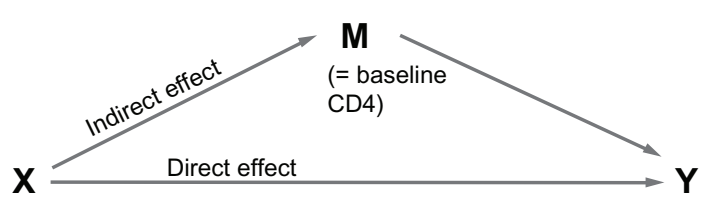

(=gender)

(=death)

Figure I Illustration of causal pathways.

Notes: The objective of the mediational analysis was to separate the effect of gender into the part explained by baseline CD4, referred to as the indirect effect, and that explained by everything else, referred to here as the direct effect. Additionally, confounders to these pathways are included in the model, but excluded from this figure. 
the indirect effect. As with any model, the model assumptions must be met and, particularly for models considering causal pathways, it is important that confounding be fully controlled. The ratio of indirect to total effects is the proportion of the effect attributable to the mediator. In this analysis we considered age as a confounder, gender as the initial variable, baseline CD4 as the mediator, and survival as the outcome.

We opted for the "product method"16 of estimating the indirect effect which required the construction of a linear regression model for baseline $\mathrm{CD} 4$ and an accelerated failure time model with a Weibull distribution using gender, baseline CD4 cell count, and age. The direct effect is immediately available from the survival model. Full details on the indirect effect estimation and the assumptions required for this model are available in the Appendix. Confidence intervals for the indirect and total effects as well as their quotient (the proportion of effect explained by CD4) were obtained by bootstrapping. ${ }^{19-22}$ All analyses were done in SAS version 9.3 (SAS Institute Inc, Cary, NC, USA) and R version 2.15 (Vienna, Austria).

\section{Ethical approval}

This study received ethical approval from the institutional review boards of the University of Ottawa and Mildmay Uganda. The Uganda National Council for Science and Technology provided additional approval.

\section{Results}

In total, 4775 patients aged 14 years or older initiated ART between January 2004 and April 2011. The median age was 33 (interquartile range [IQR] 27-39), and 1676 (35.1\%) were men. During this time period there were 200 deaths over a median follow-up time of 3.25 years (IQR 2.50-4.25); 135 patients were lost to follow-up (42 males and 93 females). Table 1 summarizes the comparison of men to women. Men tended to be older, were more likely to be married and sexually active, tended to be better educated, more likely to disclose their status to their partners, and more likely to be hepatitis B positive (odds ratio [OR]: 1.42, 95\% confidence interval [CI]: 1.10 - 1.85). Table A1 in the Appendix summarizes the comparison between patients according to vital status.

There were 84/1676 (5.0\%) deaths among men and $116 / 3099$ (3.7\%) among women. When analyzing all patients, the $P$-value for the log-rank test was 0.02 indicating a higher rate of death among men (Figure 2, Panel A). When we restricted this to the cohort involving only women who accessed care outside ANC services, the $P$-value for the logrank test was similar at 0.04 (Figure 2, Panel B).
Table I A comparison of demographic, behavioral, and clinical characteristics in men and women

\begin{tabular}{|c|c|c|c|}
\hline Variable & $\begin{array}{l}\text { Women } \\
(n=3099)\end{array}$ & $\begin{array}{l}\text { Men } \\
(n=1676)\end{array}$ & $P$-value \\
\hline Age (median [IQR]) & $32(27-39)$ & $35(28-4 I)$ & $<0.0001$ \\
\hline \multicolumn{4}{|l|}{ Marital status } \\
\hline Married/partner & 727 (23.5\%) & $653(39.0 \%)$ & \multirow[t]{3}{*}{$<0.000$ I } \\
\hline Widowed/single & $778(25.1 \%)$ & $226(13.5 \%)$ & \\
\hline NA/not reported & 1594 (5I.4\%) & 797 (47.6\%) & \\
\hline \multicolumn{4}{|l|}{ Education } \\
\hline Primary or less & $834(26.9 \%)$ & $418(24.9 \%)$ & \multirow[t]{3}{*}{0.0095} \\
\hline Some secondary or more & 742 (23.9\%) & 468 (27.9\%) & \\
\hline Not reported & $1523(49.1 \%)$ & $790(47.1 \%)$ & \\
\hline \multicolumn{4}{|l|}{ Sexually active at BL } \\
\hline Yes & 911 (29.4\%) & 708 (42.2\%) & \multirow[t]{3}{*}{$<0.0001$} \\
\hline No & $1516(48.9 \%)$ & $617(36.8 \%)$ & \\
\hline Not reported & $672(21.7 \%)$ & $351(20.9 \%)$ & \\
\hline \multicolumn{4}{|l|}{ Disclose to partner } \\
\hline Yes & $668(83.6 \%)$ & $621(91.7 \%)$ & \multirow[t]{3}{*}{$<0.0001$} \\
\hline Some & $2(0.3 \%)$ & $2(0.3 \%)$ & \\
\hline No & $129(16.1 \%)$ & $54(8.0 \%)$ & \\
\hline \multicolumn{4}{|l|}{ Partner has tested } \\
\hline Yes & $565(72.8 \%)$ & $584(86.4 \%)$ & \multirow[t]{3}{*}{$<0.0001$} \\
\hline Not reported & $6(0.8 \%)$ & $2(0.3 \%)$ & \\
\hline No & $205(26.4 \%)$ & $90(13.3 \%)$ & \\
\hline \multicolumn{4}{|l|}{ Syphilis } \\
\hline Yes & 247 (I3.4\%) & $153(15.1 \%)$ & \multirow[t]{2}{*}{0.1946} \\
\hline No & $1603(86.6 \%)$ & 857 (84.9\%) & \\
\hline \multicolumn{4}{|l|}{ Hepatitis B } \\
\hline Yes & 139 (4.5\%) & $105(6.3 \%)$ & \multirow[t]{2}{*}{0.0091} \\
\hline No & $2960(95.5 \%)$ & I57| (93.7\%) & \\
\hline \multicolumn{4}{|l|}{ Hepatitis C } \\
\hline Positive & $15(0.5 \%)$ & $5(0.3 \%)$ & \multirow[t]{2}{*}{0.4822} \\
\hline Negative & 3084 (99.5\%) & |67| (99.7\%) & \\
\hline \multicolumn{4}{|l|}{ Anemic } \\
\hline Positive & 105 (3.4\%) & 48 (2.9\%) & \multirow[t]{2}{*}{0.3890} \\
\hline Negative & 2955 (96.6\%) & I 585 (97.1\%) & \\
\hline \multicolumn{4}{|l|}{ Malaria } \\
\hline Positive & $60(6.2 \%)$ & $41(8.2 \%)$ & \multirow[t]{2}{*}{0.1576} \\
\hline Negative & 906 (93.8\%) & 457 (91.8\%) & \\
\hline
\end{tabular}

Abbreviations: $B L$, baseline; IQR, interquartile range.

Similarly, $42 \%$ of men compared to $32 \%$ of women presented for ART at WHO stage 3 or 4 (OR: 1.46; 95\% CI: 1.29-1.66) and this did not change much when ANC cases were removed (OR: $1.54 ; 95 \%$ CI: $1.37-1.75$ ). The median baseline CD4 cell count was lower in men than women. As shown in Table 2, the difference in CD4 cell count was only slightly larger, 23 versus 25 , when ANC cases were included.

The Weibull survival model shows that in univariate analysis, gender has a significant effect on survival (hazard ratio [HR]: $1.38 ; 95 \%$ CI: $1.03-1.83$ ), but in the presence of the mediators and confounders its effect is no longer significant (adjusted hazard ratio: 1.20 ; 95\% CI: $0.95-1.64$; Table 3 ). The scale coefficient of 1.87 indicates that the hazard of death is declining with time, in keeping with the fact that the majority 

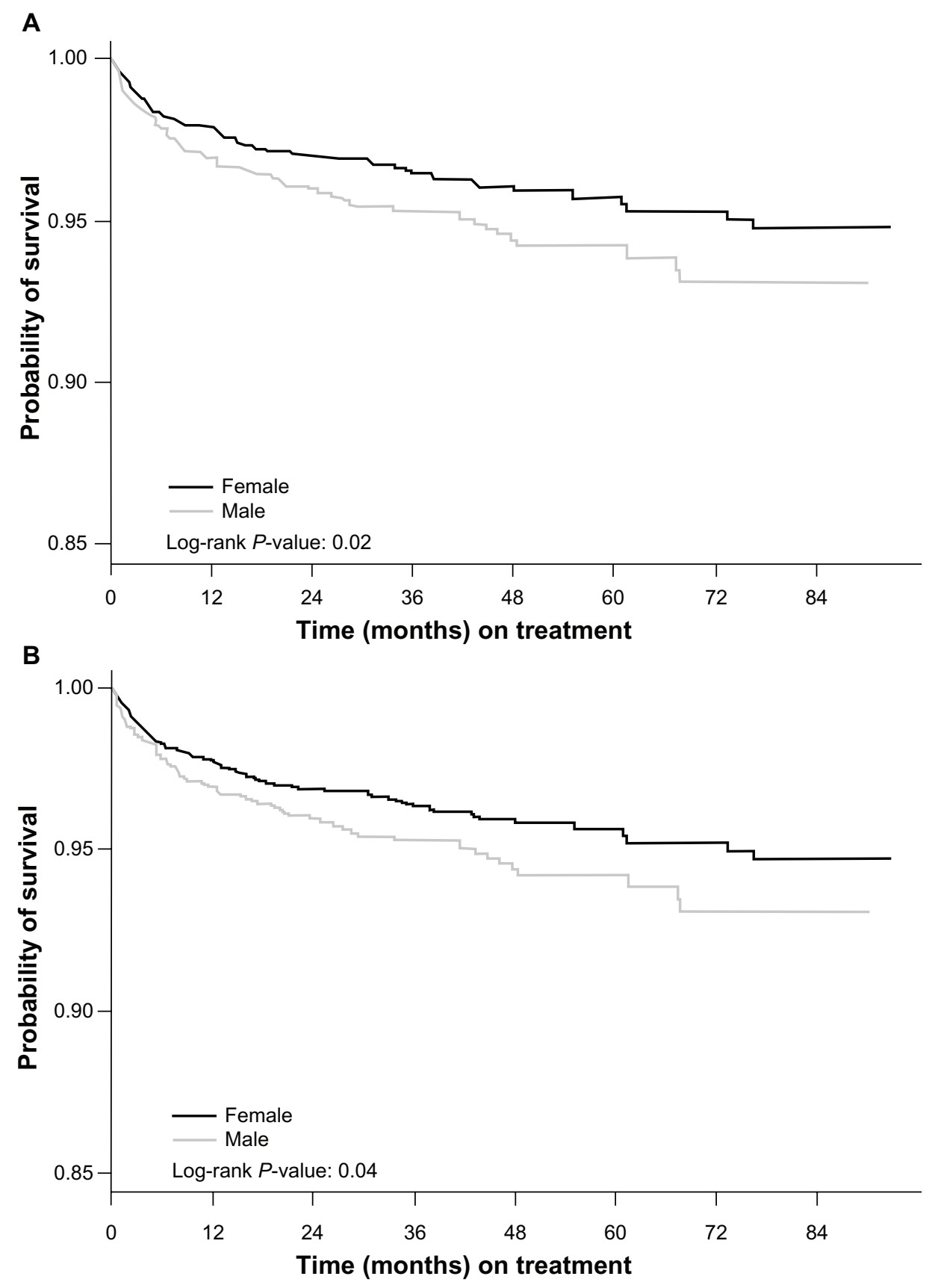

Figure 2 Kaplan-Meier survival curves for full cohort (Panel A), and Kaplan-Meier survival curves for restricted cohort (Panel B).

of the deaths occur within months of initiating ART. ${ }^{10}$ Table 4 presents the partitioning of the effect of gender into direct and indirect effects. Approximately 43\% (95\% CI: 22\%-113\%) of the additional deaths seen in men are attributable to their lower CD4 cell counts at baseline (results for reduced cohort shown in Table A2). A sensitivity analysis restricted to the sample of those not accessing care through ANC, is presented in Table A3 in the Appendix. The results were very similar.

When we examined whether single men had differing baseline risk, according to baseline $\mathrm{CD} 4$, compared with other groups, we found that single men had significantly lower CD4 (median 99, IQR 30-190) than married men (120, IQR 48-199) $[P=0.03]$ and compared to single women (144, IQR 68-209) $[P<0.0001]$.

\section{Discussion}

Although the international HIV/AIDS community has placed a particular emphasis on targeted ART of female patients, there is emerging evidence that less men engage in care for HIV/AIDS in SSA, and have less favorable outcomes. 
Table 2 Comparing disease progression at baseline between men and women with adjustments for antenatal care

\begin{tabular}{|c|c|c|c|c|c|}
\hline Sample & Variable & $\begin{array}{l}\text { Women } n(\%) \text { or } \\
\text { median (IQR) }\end{array}$ & $\begin{array}{l}\text { Men n (\%) or } \\
\text { median (IQR) }\end{array}$ & $P$-value & $\begin{array}{l}\text { Effect of gender } \\
(95 \% \mathrm{Cl})\end{array}$ \\
\hline PMTCT removed & WHO stage & & & & \\
\hline \multirow[t]{2}{*}{$(n=4537)$} & I and II & 1915 (67\%) & 973 (58\%) & $<0.0001$ & OR: I.46 \\
\hline & III and IV & $946(33 \%)$ & 703 (42\%) & & $(1.29,1.66)$ \\
\hline All included & WHO stage & & & & \\
\hline \multirow[t]{2}{*}{$(n=4775)$} & I and II & 2111 (68\%) & 973 (58\%) & $<0.0001$ & OR: 1.54 \\
\hline & III and IV & $988(32 \%)$ & 703 (42\%) & & $(1.37,1.75)$ \\
\hline $\begin{array}{l}\text { PMTCT removed } \\
(\mathrm{n}=4537)\end{array}$ & $\begin{array}{l}\text { Baseline CD4 } \\
\left(\text { cells } / \mathrm{mm}^{3}\right)\end{array}$ & $147(68,212)$ & $124(43,205)$ & $<0.000$ I & $18(11,25)^{*}$ \\
\hline $\begin{array}{l}\text { All included } \\
(\mathrm{n}=4775)\end{array}$ & $\begin{array}{l}\text { Baseline CD4 } \\
\left(\text { cells } / \mathrm{mm}^{3}\right)\end{array}$ & 149 (7I, 2I5) & $124(43,205)$ & $<0.0001$ & $20(13,27)^{*}$ \\
\hline
\end{tabular}

Note: *These are confidence intervals for the difference in mean CD4 cell counts at baseline between women and men.

Abbreviations: $\mathrm{Cl}$, confidence interval; OR, odds ratio; IQR, interquartile range, PMTCT, prevention of mother to child transmission; WHO, World Health Organization.

A proposed reason for this inconsistency is that antenatal care provides a platform through which women can access care more frequently and earlier in their disease progression. ${ }^{23}$ Our study found that men had an increased risk of death and nearly half the additional deaths appear to be attributable to delayed engagement in care. In the multivariable model, we divided the effect of gender into the direct effect and the indirect effect (effect due to CD4 at baseline). Therefore, the fact that gender is not significant in the multivariable model, implies that the increased risk observed in men is not due to their gender, but mostly due to their lower baseline CD4 cell counts. ANC accounted for only a small fraction of this inconsistency. A sustained effort to reduce this discrepancy could have an important impact both on the individuals and the community.

Our study has several strengths and limitations. Our study had low rates of death and low rates of loss to follow-up. The Mildmay program puts emphasis on community care that may explain the high retention to care, an observation mirrored in other community-based care programs. ${ }^{24}$ Although there is accumulating evidence that men across SSA are at increased risk of morbidity and mortality in comparison to women,${ }^{25}$ our study was restricted to a single cohort in Uganda. Our sample

Table 3 Survival analysis using an Accelerated Failure Time model with a Weibull distribution

\begin{tabular}{lll}
\hline Variable & $\begin{array}{l}\text { Unadjusted } \\
\text { hazard ratios } \\
\text { (95\% confidence } \\
\text { interval) }\end{array}$ & $\begin{array}{l}\text { Adjusted } \\
\text { hazard ratios } \\
\text { (95\% confidence } \\
\text { interval) }\end{array}$ \\
\hline $\begin{array}{l}\text { Gender } \\
\text { Male vs female }\end{array}$ & $\mathrm{I} .38(\mathrm{I} .03, \mathrm{I} .83)$ & $\mathrm{I} .20(0.95, \mathrm{I} .64)$ \\
CD4 count (fourth root) & $0.58(0.45,0.74)$ & $0.58(0.45,0.74)$ \\
Age at initiation & $\mathrm{I} .02(\mathrm{I} .00, \mathrm{I} .03)$ & $\mathrm{I} .02(\mathrm{I} .0 \mathrm{I}, \mathrm{I} .03)$ \\
Scale & $\mathrm{N} / \mathrm{A}$ & $\mathrm{I} .87(\mathrm{I} .64,2.14)$ \\
\hline
\end{tabular}

is not random and may not be representative. Our bivariate analyses reveal that our cohort has a relatively higher number of married men, suggesting that the engagement of women has led them to bring their husbands into care. Consequently the differences in disease progression reported in this cohort may underestimate the discrepancy in the community.

The role of antenatal care in the discrepancy between how men and women seek access to healthcare is often acknowledged, but seldom analyzed in detail. Our study clearly shows the existence of other, more important factors at the source of the divide. It is well known that initiating care at a lower CD4 cell count increases the risk of mortality. ${ }^{26}$ Therefore it is not surprising that our results show that the increased mortality in men can in part be explained by later initiation. Nonetheless, by quantifying the proportion of increased mortality attributable to later initiation we have highlighted the urgency of increasing engagement to care.

SSA continues to be the epicenter of the HIV/AIDS pandemic. Engagement in care remains an important challenge in the fight against HIV. Men are seldom targeted because they do not fall into our conventional definitions of vulnerability and marginality. ${ }^{27}$ On the contrary, in general, men are recognized for having poor health-seeking behavior, so that efforts to engage them are even more critical.

Table 4 Partitioning the effect of gender through the Weibull model

\begin{tabular}{ll}
\hline Effect & $\begin{array}{l}\text { Estimate } \\
\mathbf{( 9 5 \% ~ c o n f i d e n c e ~ i n t e r v a l ) ~}\end{array}$ \\
\hline Direct effect & $-0.30(-0.65,0.05)$ \\
Indirect effect & $-0.20(-0.26,-0.15)$ \\
Total effect & $-0.50(-0.85,-0.15)$ \\
Indirect effect/total effect* & $0.43(0.22,1.13)$ \\
\hline
\end{tabular}

Note: $*$ The ratio of indirect effect to total effect represents the proportion of the effect of gender on mortality explained by CD4 cell count at baseline. 
Efforts to engage men do exist. In Swaziland, the Ministry of Health has initiated men's health days. ${ }^{28}$ Studies have shown that home-based testing programs are allowing men to test earlier, giving them a chance to engage in a timely fashion. ${ }^{29}$ Encouraging men to accompany women in antenatal care, as recommended by WHO in Uganda, has had some success in Rwanda and may have a role in other settings, ${ }^{30}$ although this would only target couples with active relationships. Circumcision clinics may represent a one-time testing opportunity for single men. The implementation of programs to encourage further participation by men in care is a difficult task, but earlier recruitment into care remains the best method to align the health outcomes of men with those of women.

\section{Conclusion}

A growing number of studies are reporting that among HIVpositive individuals on ART in SSA, men tend to be at higher risk of death as was the case in our cohort. Little has been done to determine the underlying causes that are crucial to making changes to the health systems that create them. Our study found that among the leading causes, and quite possibly the leading cause, is the lower CD4 cell counts at which men on average present themselves for ART initiation. Targeted campaigns need to continue to be evaluated, to reduce the gender disparity and improve testing, linkage to care, and ultimately health outcomes for men. This study can contribute to the growing body of evidence designed to inform evidence-based policy, to reduce barriers to healthcare experienced by men. Finally, antenatal care programs are a key difference in how men and women access care and are often cited as a plausible cause for observed differences in health outcomes, yet this difference did not appear to have a large impact in our cohort. Our findings suggest that further investigation is needed as access to care through antenatal care may play a more muted role than believed in explaining the differences in ART uptake between men and women.

\section{Author contributions}

The study design was conceived by SK, NF, EJM, and ED. Data were acquired by SK, MN, DM, MO, MK, WM, SY and AF. The analyses were conducted by SK, AF, and EJM. SK wrote the manuscript and all contributed to writing. The final manuscript was approved by all.

\section{Funding}

The Canadian Institutes of Health Research (CIHR) provided funding for this analysis. No funding agency has seen this study.

\section{Disclosure}

No authors have any competing interests.

\section{References}

1. Ford N, Calmy A, Mills EJ. The first decade of antiretroviral therapy in Africa. Global Health. 2011;7:33.

2. Mills EJ, Bakanda C, Birungi J, et al. Life expectancy of persons receiving combination antiretroviral therapy in low-income countries: a cohort analysis from Uganda. Ann Intern Med. 2011;155:209-216.

3. WHO, UNAIDS, UNICEF. Global HIV/AIDS Response: Epidemic Update and Health Sector Progress Towards Universal Access. Geneva, Switzerland: World Health Organization; 2011.

4. Mills EJ, Ford N. Home-based HIV counseling and testing as a gateway to earlier initiation of antiretroviral therapy. Clin Infect Dis. 2012;54:282-284

5. Exner T, Gardos P, Seal D, Ehrhadrt A. HIV sexual risk interventions with hetersexual men: the forgotten group. AIDS Behaviour. 1999;3: 347-358.

6. Higgins JA, Hoffman S, Dworkin SL. Rethinking gender, heterosexual men, and women's vulnerability to HIV/AIDS. Am J Public Health. 2010; $100: 435-445$.

7. Mills EJ, Ford N, Mugyenyi P. Expanding HIV care in Africa: making men matter. Lancet. 2009;374:275-276.

8. Mills EJ, Bakanda C, Birungi J, et al. Male gender predicts mortality in a large cohort of patients receiving antiretroviral therapy in Uganda. J Int AIDS Soc. 2011;14:52.

9. Braitstein P, Boulle A, Nash D, et al. Gender and the use of antiretroviral treatment in resource-constrained settings: findings from a multicenter collaboration. $J$ Womens Health (Larchmt). 2008;17: $47-55$.

10. Braitstein P, Brinkhof MW, Dabis F, et al. Mortality of HIV-1infected patients in the first year of antiretroviral therapy: comparison between low-income and high-income countries. Lancet. 2006;367: $817-824$.

11. Druyts E, Dybul M, Kanters S, et al. Male gender and the risk of mortality among individuals enrolled in antiretroviral treatment programs in Africa: a systematic review and meta-analysis. AIDS. 2013;27: 417-425.

12. Johannessen A. Are men the losers of the antiretroviral treatment scale-up? AIDS. 2011;25:1225-1226.

13. May M, Boulle A, Phiri S, et al. Prognosis of patients with HIV-1 infection starting antiretroviral therapy in sub-Saharan Africa: a collaborative analysis of scale-up programmes. Lancet. 2010;376:449-457.

14. Funk A, Kanters S, Nansubuga M, et al. Cohort Profile: The MUg Observational Cohort. Int J Epidemiol. 2012;41(6):1594-1594.

15. Egger M, Spycher BD, Sidle J, et al. Correcting mortality for loss to follow-up: a nomogram applied to antiretroviral treatment programmes in sub-Saharan Africa. PLoS Med. 2011;8:e1000390.

16. Baron RM, Kenny DA. The moderator-mediator variable distinction in social psychological research: conceptual, strategic, and statistical considerations. J Pers Soc Psychol. 1986;51:1173-1182.

17. Lange T, Hansen JV. Direct and indirect effects in a survival context. Epidemiology. 2011;22:575-581.

18. Tein J-Y, MacKinnon D, Yanai H, et al, editors. Estimating mediated effects with survival data. In: New Developments on Psychometrics. Tokyo: Springer-Verlag Tokyo Inc; 2003:405-412.

19. VanderWeele TJ. Causal mediation analysis with survival data. Epidemiology. 2011;22:582-585.

20. Efron B. Bootstrap methods: another look at the jackknife. Annals of Statistics. 1979;7:1-26.

21. Efron BRJT. An Introduction to the Bootstrap. New York: Chapman and Hall; 1993.

22. Vanderweele TJ, Vansteelandt S. Odds ratios for mediation analysis for a dichotomous outcome. Am J Epidemiol. 2010;172:1339-1348. 
23. Kuwane B, Appiah K, Felix M, Grant A, Churchyard G. Expanding HIV care in Africa: making men matter in Johannesburg. Lancet. 2009;374:1329.

24. Decroo T, Telfer B, Biot M, et al. Distribution of antiretroviral treatment through self-forming groups of patients in Tete province, Mozambique. J Acquir Immune Defic Syndr. 2011:56:e39-e44.

25. Druyts E, Dybul M, Kanters S, et al. Male gender and the risk of mortality among individuals enrolled in antiretroviral treatment programs in Africa: A systematic review and meta-analysis. AIDS. 2013;27(3):417-425.

26. Mills EJ, Bakanda C, Birungi J, Yaya S, Ford N; TASO-CAN Writing Group. The prognostic value of baseline CD4 cell count beyond 6 months of antiretroviral therapy in HIV positive patients in Uganda. AIDS. 2012;26:1425-1429.

27. Mills EJ, Beyrer C, Birungi J, Dybul MR. Engaging men in prevention and care for HIV/AIDS in Africa. PLoS Med. 2012;9:e1001167.
28. Swaziland US Global Health Initiative Country Strategy: Government of the Kingdom of Swaziland - United States Government; February 10, 2012.

29. Wachira J, Kimaiyo S, Ndege S, Mamlin J, Braitstein P. What is the impact of home-based HIV counseling and testing on the clinical status of newly enrolled adults in a large HIV care program in Western Kenya? Clin Infect Dis. 2012;54:275-281.

30. Asiimwe A. HIV Treatment for prevention: a view from the ground. 20th Conference on Retroviruses and Opportunistic Infections (CROI); March 5-8, 2012; Atlanta, Ga, USA.

31. Robins JM, Greenland S. Identifiability and exchangeability for direct and indirect effects. Epidemiology. 1992;3(2):143-155.

32. Pearl J. Direct and indirect effects. Seventeenth Conference on Uncertainty and Artificial Intelligence; 2001; San Francisco. 


\section{Appendix}

The "product method" of estimating the indirect effect requires the construction of a linear regression model for baseline CD4 cell count and an accelerated failure time model with a Weibull distribution using gender, baseline CD4 cell count and age. The baseline CD4 cell count was transformed using a fourth root in order to meet the conditions required for linear regression. Let $\beta_{1}$ be the coefficient of gender in this model. The Weibull model was chosen over Cox proportional-hazards regression because the latter does not allow for the partitioning of a direct and indirect effect. The conditions required for the Weibull model were also verified and met. The survival model was fit using gender, baseline CD4 cell count, and age. The coefficient for gender is the direct effect and a confidence interval is readily available. The indirect effect is estimated by the product $\beta_{1} \theta_{2}$, where $\theta_{2}$ is the coefficient for baseline CD4 cell count. This approach to mediational modeling is built upon the counterfactual paradigm as established by Robins and Greenland ${ }^{31}$ and more directly by Pearl. ${ }^{32}$ Four assumptions are listed as requirements to these methods: (i) no confounding for the exposureoutcome relationship, (ii) no confounding for the mediatoroutcome relationship, (iii) no confounding for the exposuremediator relationship, and (iv) no mediator-outcome confounder that is an effect of the exposure. As opposed to studies where the exposure is a treatment, in this study there is no interest in estimating the direct effect of gender on survival. The total effect of gender is comprised of many pathways including: disease progression at initiation, retention to care, and adherence to treatment. The objective here is to tease out the proportion of total effect on the baseline CD4 pathway. As such, some confounders to the exposure-outcome relationship were not considered. Age is always a confounder when survival is the outcome and was included in all models. To the best of our knowledge, there are no reported confounders to the relationship between baseline CD4 and survival in the literature. Thus, assumptions (ii) and (iii) seem fair. Given that the mediator is a baseline variable, assumption (iv) should also be met.

Table Al A comparison of demographic, behavioral, and clinical characteristics across survival groups

\begin{tabular}{|c|c|c|c|}
\hline Variable & $\begin{array}{l}\text { Alive } \\
(n=4575)\end{array}$ & $\begin{array}{l}\text { Dead } \\
(n=200)\end{array}$ & $P$-value \\
\hline Age [median (IQR)] & $33(27,40)$ & $34(27.5,4 I)$ & 0.0721 \\
\hline \multicolumn{4}{|l|}{ Sex } \\
\hline Female & $2983(65.2 \%)$ & II 6 (58.0\%) & 0.0409 \\
\hline Male & 1592 (34.8\%) & $84(42.0 \%)$ & \\
\hline \multicolumn{4}{|l|}{ Marital status } \\
\hline Married/partner & $1326(29.0 \%)$ & $54(27.0 \%)$ & 0.1982 \\
\hline Widowed/single & 970 (21.2\%) & $34(17.0 \%)$ & \\
\hline NA/not reported & 2279 (49.8\%) & $112(56.0 \%)$ & \\
\hline \multicolumn{4}{|l|}{ Education } \\
\hline Primary or less & 1203 (26.3\%) & 49 (24.5\%) & 0.7300 \\
\hline Some secondary or more & II 55 (25.2\%) & 55 (27.5\%) & \\
\hline Not reported & 2217 (48.5\%) & $96(48.0 \%)$ & \\
\hline \multicolumn{4}{|l|}{ Sexually active at BL } \\
\hline Yes & 1562 (34.1\%) & $57(28.5 \%)$ & 0.1246 \\
\hline No & 2030 (44.4\%) & $103(51.5 \%)$ & \\
\hline Not reported & $983(21.5 \%)$ & $40(20.0 \%)$ & \\
\hline \multicolumn{4}{|l|}{ Disclose to partner } \\
\hline Yes & 1289 (87.5\%) & 45 (83.3\%) & 0.3966 \\
\hline Some & $4(0.3 \%)$ & $0(0 \%)$ & \\
\hline No & $174(12.2 \%)$ & $9(16.7 \%)$ & \\
\hline \multicolumn{4}{|l|}{ Partner has tested } \\
\hline Yes & 1112 (79.5\%) & 37 (68.5\%) & 0.1121 \\
\hline Some & $8(0.6 \%)$ & $0(0 \%)$ & \\
\hline No & $278(19.9 \%)$ & 17 (3I.5\%) & \\
\hline \multicolumn{4}{|l|}{ Syphilis } \\
\hline Yes & $396(14.5 \%)$ & $16(12.9 \%)$ & 0.6960 \\
\hline No & 2340 (85.5\%) & $108(87.1 \%)$ & \\
\hline \multicolumn{4}{|l|}{ Hepatitis B } \\
\hline Yes & $228(5.0 \%)$ & $16(8.0 \%)$ & 0.1072 \\
\hline No & 4347 (95.0\%) & $184(92.0 \%)$ & \\
\hline \multicolumn{4}{|l|}{ Hepatitis C } \\
\hline Positive & $20(0.4 \%)$ & $0(0 \%)$ & 1.000 \\
\hline Negative & 4555 (99.6\%) & $200(100 \%)$ & \\
\hline \multicolumn{4}{|l|}{ Anemic } \\
\hline Positive & II 3 (2.5\%) & 40 (21.2\%) & $<0.000$ I \\
\hline Negative & 4391 (97.5\%) & 149 (78.8\%) & \\
\hline \multicolumn{4}{|l|}{ Malaria } \\
\hline Positive & 98 (7.2\%) & $3(3.1 \%)$ & 0.1483 \\
\hline Negative & 1270 (92.8\%) & $93(96.9 \%)$ & \\
\hline
\end{tabular}

Abbreviations: BL, baseline; IQR, interquartile range. 
Table A2 Partitioning the effect of gender through the Weibull model for all four cases analyzed

\begin{tabular}{lllll}
\hline Variable & $\begin{array}{l}\text { Full cohort, LoF } \\
\text { adjusted }\end{array}$ & $\begin{array}{l}\text { Reduced cohort, LoF } \\
\text { adjusted }\end{array}$ & Full cohort & Reduced cohort \\
\hline Direct effect & $-0.33(-0.65,0.01)$ & $-0.37(-0.77,0.03)$ & $-0.30(-0.65,0.05)$ & $-0.34(-0.73,0.05)$ \\
Indirect effect & $-0.17(-0.21,-0.13)$ & $-0.17(-0.22,-0.13)$ & $-0.20(-0.26,-0.15)$ & $-0.21(-0.27,-0.16)$ \\
Total effect & $-0.49(-0.82,-0.17)$ & $-0.54(-0.90,-0.19)$ & $-0.50(-0.85,-0.15)$ & $-0.54(-0.89,-0.19)$ \\
Indirect effect/ & $0.41(0.18,0.89)$ & $0.35(0.15,0.84)$ & $0.43(0.22,1.13)$ & $0.34(0.15,0.87)$ \\
total effect* & & & &
\end{tabular}

Note: *The ratio of indirect effect to total effect represents the proportion of the effect of gender on mortality explained by CD4 cell count at baseline.

Abbreviation: LoF, lost to follow-up.

Table A3 Survival analysis using an Accelerated Failure Time model with a Weibull distribution (sensitivity analyses)

\begin{tabular}{|c|c|c|}
\hline Variable & $\begin{array}{l}\text { Unadjusted } \\
\text { hazard ratios } \\
\text { ( } 95 \% \text { confidence } \\
\text { interval) }\end{array}$ & $\begin{array}{l}\text { Adjusted } \\
\text { hazard ratios } \\
\text { ( } 95 \% \text { confidence } \\
\text { interval) }\end{array}$ \\
\hline \multicolumn{3}{|c|}{ Restricted cohort with adjustments for loss to follow-up } \\
\hline \multicolumn{3}{|c|}{ Gender } \\
\hline Male vs female & $1.35(1.04,1.76)$ & $1.23(0.96,1.61)$ \\
\hline CD4 count (fourth root) & $0.59(0.5 \mathrm{I}, 0.67)$ & $0.59(0.5 \mathrm{I}, 0.67)$ \\
\hline Age at initiation & $\mathrm{I} .0 \mathrm{I}(\mathrm{I} .00, \mathrm{I} .02)$ & $1.01(1.00,1.02)$ \\
\hline Scale & N/A & $1.76(1.56,1.99)$ \\
\hline \multicolumn{3}{|c|}{ Full cohort without adjustments for loss to follow-up } \\
\hline \multicolumn{3}{|c|}{ Gender } \\
\hline Male vs female & $1.34(1.01,1.76)$ & $1.18(0.88,1.57)$ \\
\hline CD4 count (fourth root) & $0.60(0.47,0.76)$ & $0.59(0.47,0.76)$ \\
\hline Age at initiation & $1.02(1.00,1.03)$ & $1.02(1.01,1.03)$ \\
\hline Scale & $\mathrm{N} / \mathrm{A}$ & $1.88(1.63,2.15)$ \\
\hline \multicolumn{3}{|c|}{ Restricted cohort without adjustments for loss to follow-up } \\
\hline \multicolumn{3}{|c|}{ Gender } \\
\hline Male vs female & $1.38(1.03,1.83)$ & $1.20(0.95,1.64)$ \\
\hline CD4 count (fourth root) & $0.58(0.45,0.74)$ & $0.58(0.45,0.74)$ \\
\hline Age at initiation & $1.02(1.00,1.03)$ & $1.02(1.01,1.03)$ \\
\hline Scale & N/A & $1.87(1.64,2.14)$ \\
\hline
\end{tabular}

HIV/AIDS - Research and Palliative Care

\section{Publish your work in this journal}

HIV/AIDS - Research and Palliative Care is an international, peerreviewed open-access journal focusing on advances in research in HIV, its clinical progression and management options including antivira treatment, palliative care and public healthcare policies to control viral spread. The journal welcomes original research, basic science, clinical \& epidemiological studies, reviews \& evaluations, expert opinion \& commentary, case reports \& extended reports. The manuscript management system is completely online and includes a very quick and fair peer-review system. Visit http://www.dovepress.com/ testimonials.php to read real quotes from published authors. 